\title{
نقل حركة الهمزة في العربيّة \\ دراسة لغوية مقارنة بين القراءات القرآنية واللهجة الفلسطينية
}

تقي الدين مصطفى عبد الباسط التميمي

أستاذ مشارك- جامعة فلسطين التقنية/ خضوري- فرع العروب- فلسطين taqitammi@gmail.com 
المجلة الدولية للدراسات اللغوية والأدبية العربية

International Journal for Arabic Linguistics and Literature Studies (JALLS)

www.refaad.com

Journal Homepage: https://www.refaad.com/views/JALS/home.aspx

ISSN : 2663-5860(Online) 2663-5852(Print)

\title{
نقل حركة الهمزة في العربيّة
}

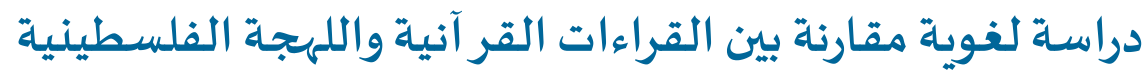

\author{
تقي الدين مصطفى عبد الباسط التميهي \\ أستاذ مشارك- جامعة فلسطين التقنية/ خضوري- فرع العروب- فلسطين \\ taqitammi@gmail.com
}

DOI: https://doi.org/10.31559/JALLS2021.3.4.2 2021/12/19 2021/11/4 مراجعة البحث: 2021/7 قبول البحث

الملتخص:

تجمع هذه الدراسة بين الأصالة والتّراث المتمثّل في نقل حركة الهمزة للسيّاكن قبلها في اللّرجة الفلسطينيّة الحديثة، وربط ذلك

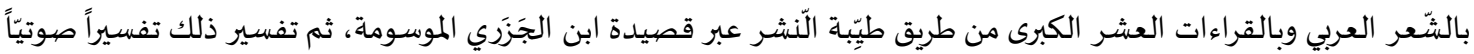

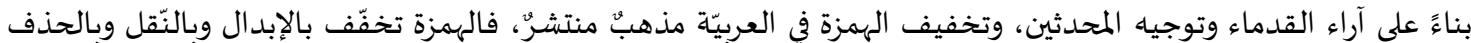
وبالإدخال وغيرها. الكلمات المفتاحيّة: همزة؛ نقل؛ لهجة؛؛ القراءات القرآنيّة.

تعد اللهجةُ الفلسطينيةٌ امتد اداً للهجات العرب القديمة الممتدّة عبر مئات السيّنين، وتعد فلسطين مقراً ومستقراً للقبائل العربيّة

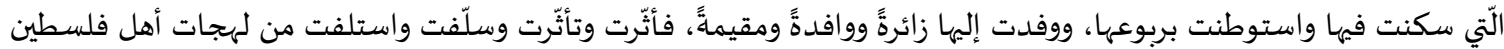

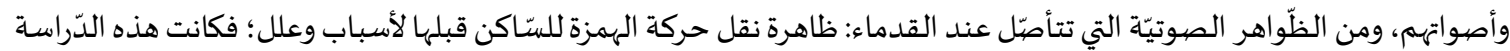

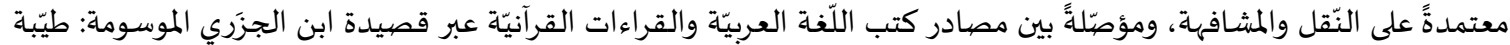

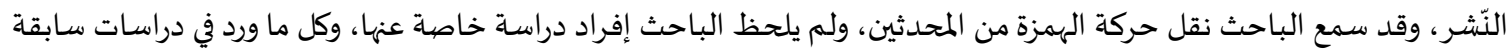

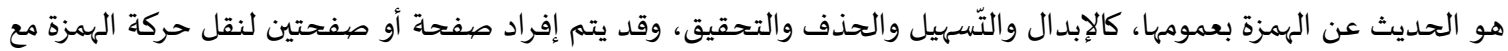
حذفها؛ فكانت هذه الدراسة تجميعاً لما تشتّت في مصادر القدماء ثم تفسيرها وتوضيحها، وقد الهند استخدم الباحث المنهج الاستقرائي

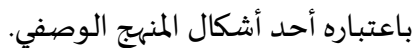

\section{المبحث الأول: مدخل وتعريفات}

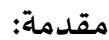

تعد الهمزة إحدى أصهوات العربيّة، ووصفها القدماء والمحدثون بصعوبة نطقها؛ فهي تخرج من أقصى الحلق مهتوتةً مضغوطةً

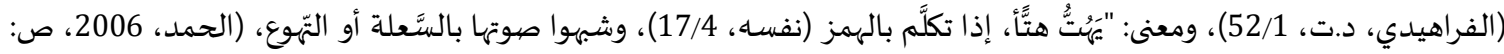

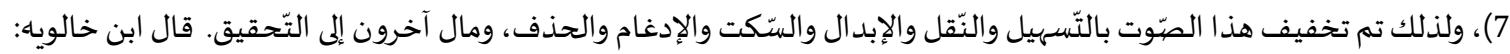
العرب تتّسع في الهمزة ما لا تتّسع في غيره، فتحقّق وتلين وتبدل وتطرح (ابن خالوياه، 1981، 69/1)، فهو صوت بهوت مجهور عند سيبويها

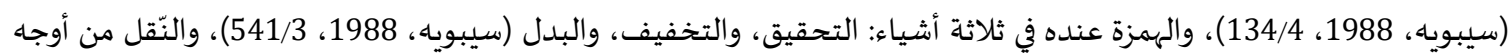
تخفيف الهمزة، ويؤكّد المحدثون على انحباس الهواء خلف الوترين الصوتيين، ثم انفراجهما فيخرج الهواء محدثاً صهوتاً مسموعاً هو 


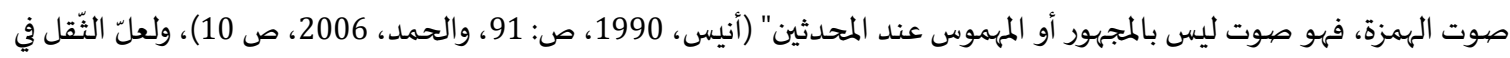

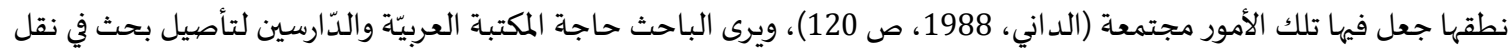

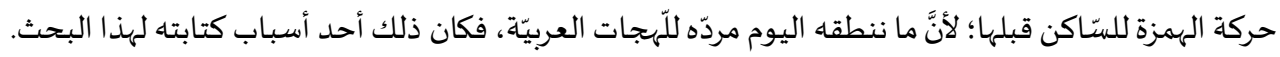

المطلب الأول: تعريف نقل حركة الهمزة لغةًً واصطلاحاً

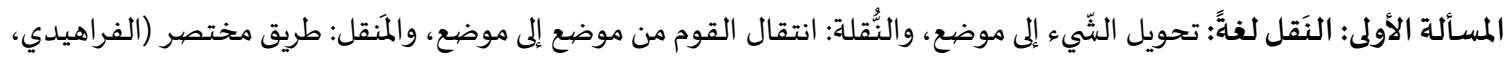

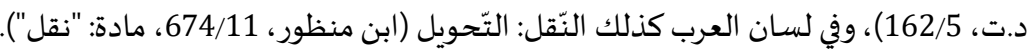

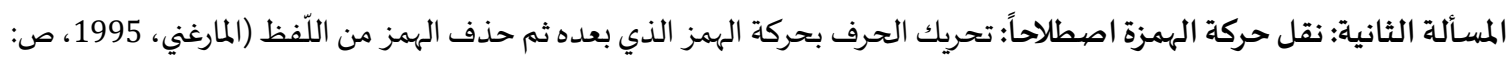

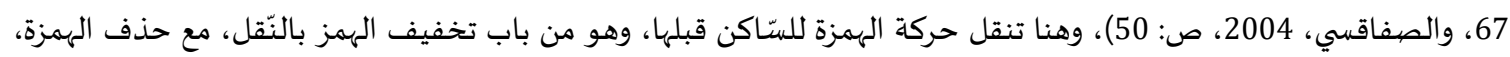

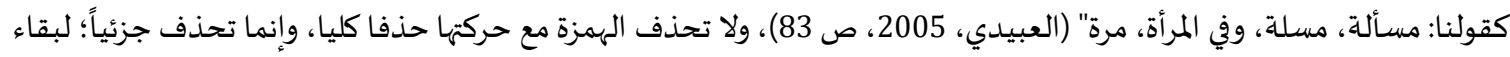
أثر الهمزة وهو الحركة. المسألة الثالثة: تأصيل نقل الهمزة عند القدماء: الهماء:

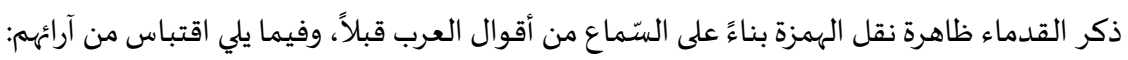
أولاً: الفراهيدي: ت: 170هـ، تحدّث عن تخفيف الهمزة بالنّقل عبر حديثه عن جمع كلمة مسألة: مسائل، فإذا حذأ حذفوا الهمزة قالوا:

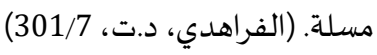

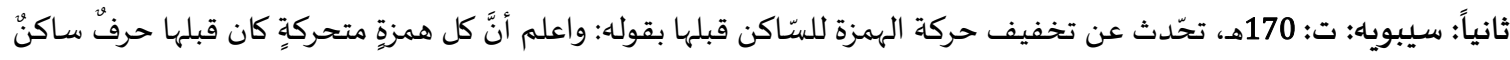

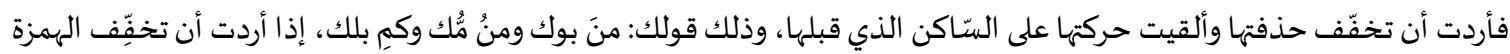

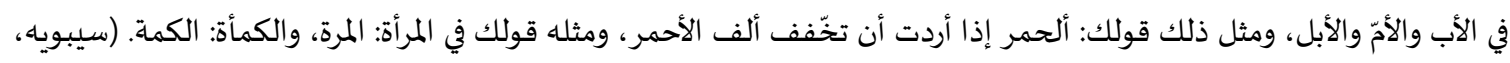

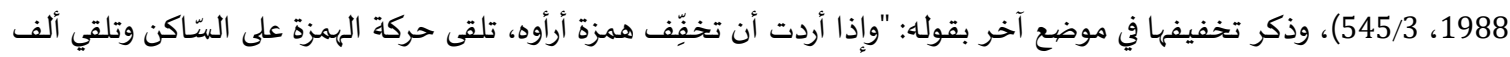

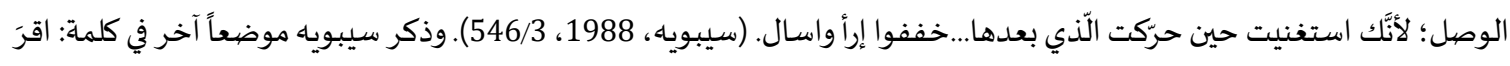

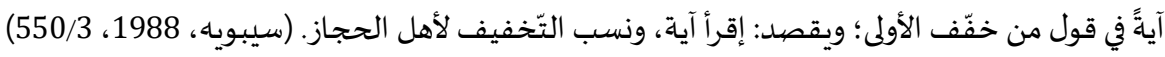

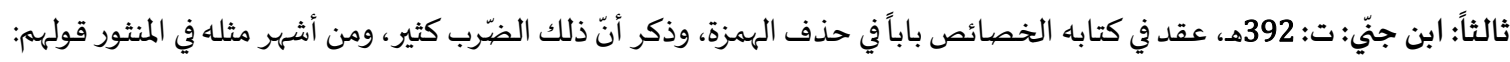

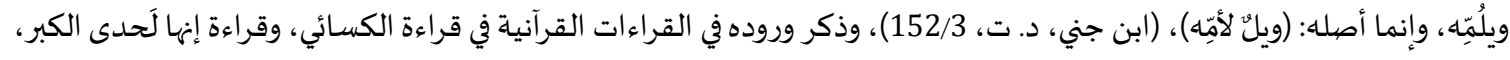

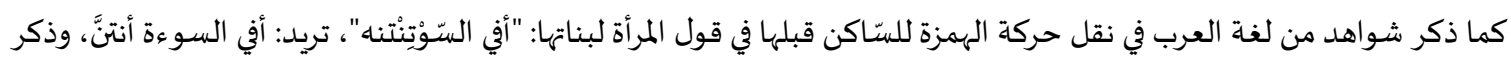

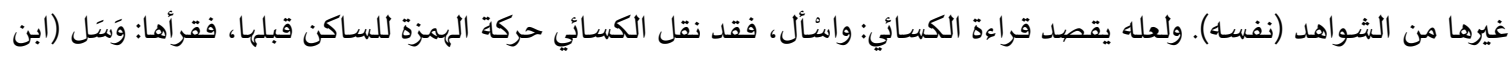

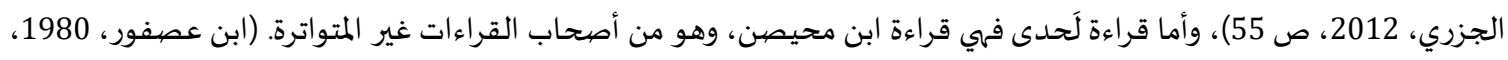

(100/1

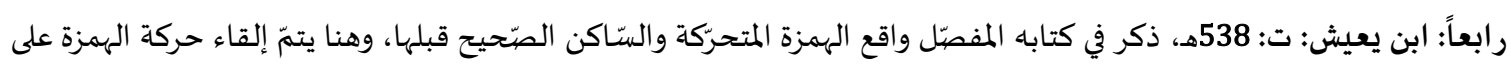

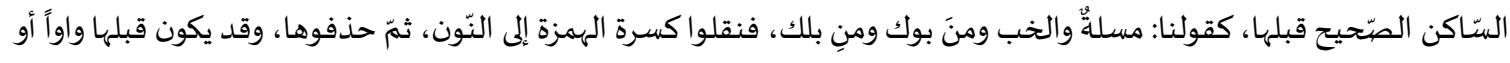

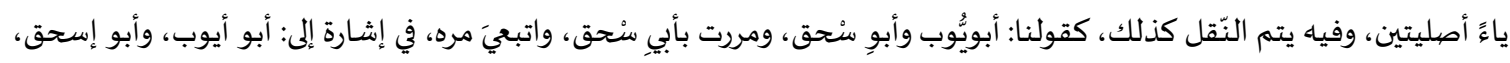

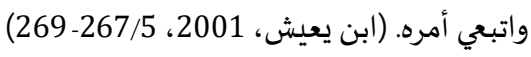

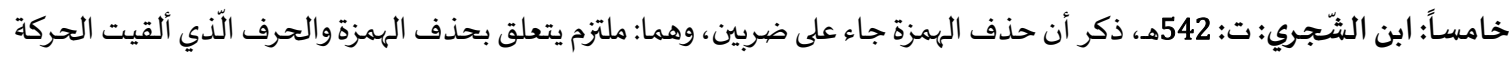

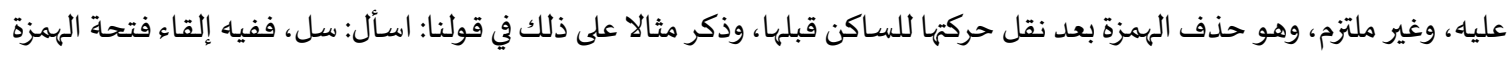

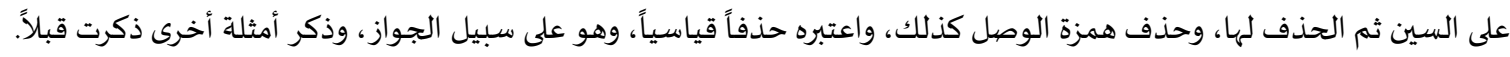

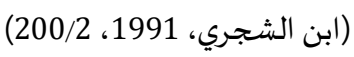

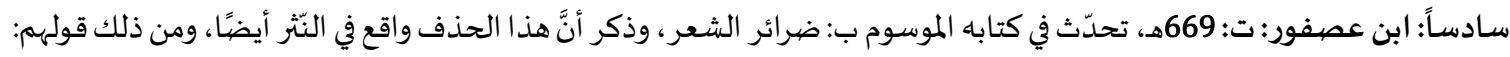

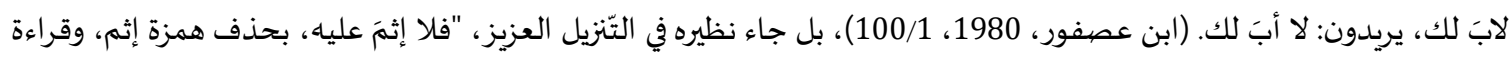

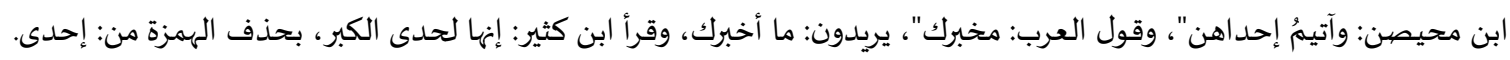

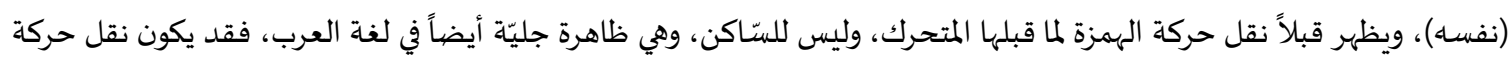

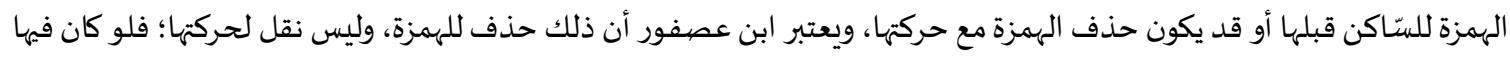

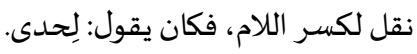


سابعاً: البغدادي: ت: 1093ه، ذكر في كتابه خزانة الأدب قول الشّّاعر: ألا هلَ اتاك والأنباء تنهي، فقال: فيه نقل حركة الهمزة من

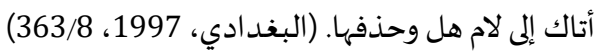

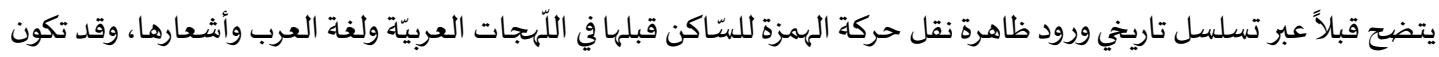

تحت عنوان تخفيف الهمزة بالنّقل. كما ورد تأصيل نقل حركة الهمزة للسيّاكن قبلها عند أصحاب كتب القراءات مجتمعة؛ لأها وردت في باب أصول القراءات وفي

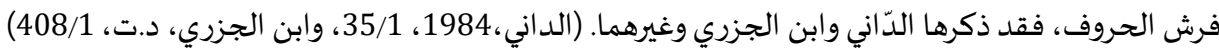

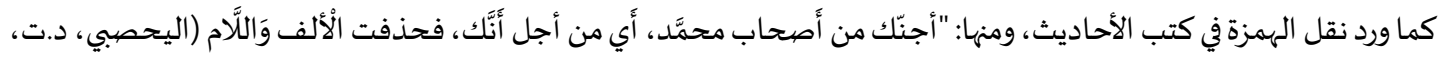

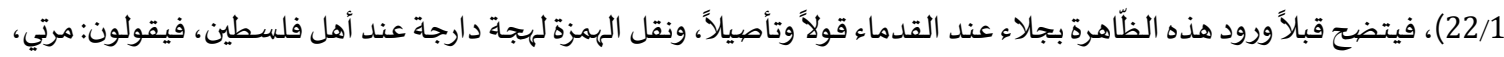
عوضا عن امرأتي، وسمع الباحث من أهل فلسطين يقولون: "مينُمَكَ" و"مينَبوك" و"أمَحمد" في إشـارة لقولهه: مين أمك ومين أبوك وأم أحمد، كما سيظهر لاحقاً.

$$
\text { المطلب الثّاني: نقل حركة الهمزة للساكن قبلها في الشعر العربي }
$$

ورد في الشعر العببي القديم تخفيف الهمز بالنقل، واعتبره ابن جني للضيرورة (ابن جني، د.ت، الهزة 152/3)، وذُكرت الأشعار في مصادر كتب الشعر ومراجعها، وفي شبكة المعلومات ((http://www.rabitat- alwaha.net/moltaqa/showthread.php?t=32614)، وقد ورد في أشعار كثيرة، ومنها: عَجَلانَ ذا زادِ وَغَيَرَمُزَوَّدِ

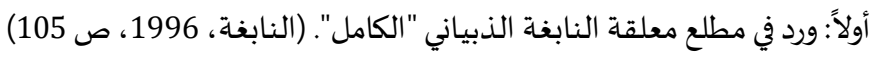
أَمِن آل ميَّة رائحِ أم مُغْتد فالتفعيلات: متَفاعلن متَفاعلن متْفاعلن، والشـاهد: أمِنال"، فيختل وزن البيت إذا لم يتم نقل الهمز، وفي حال النقل للهمز يصبح

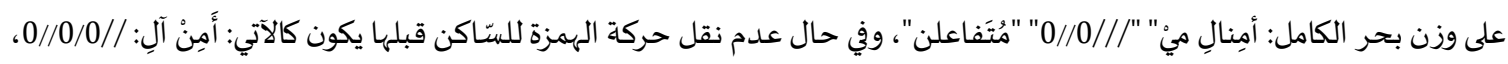

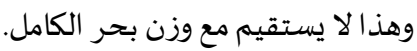

أَوَاشبهَهَهُ أَو كَانَ مِنهُ مُدانِيا

ثانياً: ورد في قول مجنون ليلي "الطويل" (قيس، د.ط، ص 42)

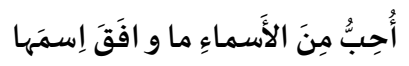

فالتفعيلات: فعولُ مفاعيلن فعولٌ مفاعِلن، والشَاهد: "أوَشْبَهَه"، فيختل وزن البيت إذا لم يتم نقل الهمز، وفي حال النقل للهمز

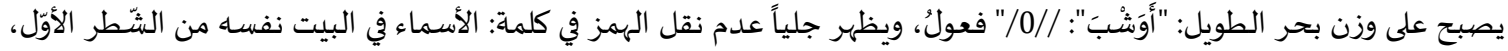
ولجوء الشاعر إلى التحقيق حتى يستقيم وزن البيت، وبذلك يكون الشـاعر قد أتى بلغتين من لغات العرب في تحقيق الهمز وتخفيفه

ثالثاً: ورد في قول جميل بثينة: "الطويل" (جميل، 1982، ص 83) لوَ آبصرُهُ الواشي للقُرَتْْ بلابلُهُ و إنِّي لأَرْضَى مِنْ نَوَالِلكِ بالَّذي

فالتفعيلات: فعولٌ مفاعيلٌ فعولُ مفاعِلن، والشاهد: "لَوَنْصره"، فوزن: "لَوَبَصَ" فعول: //0/، فيختل وزن البيت إذا لم يتم نقل

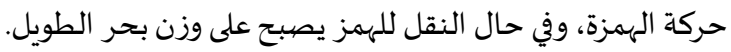
رابعاً: ورد في قول كعب بن زهير: "البسيط" (كعب، 1997، ص 61)

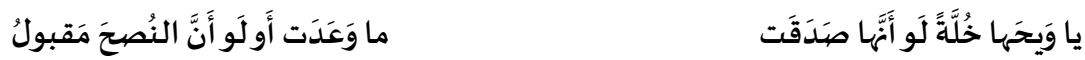

فالتفعيلات: مستفعلن فاعلن مستفعلن فَعِلن، والشاهد: نقل همزة أنّ في: لو أن، فأصبحت: لوَنَّ؛ لأن عدم النقل يُخِل من وزن

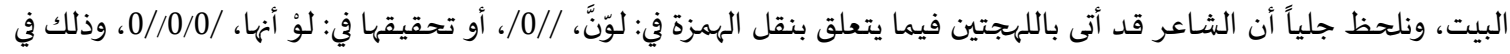
الشطر الأول من البيت نفساء. خامساً: ورد في قول عنترة: "الكامل" (عنترة، 1964، ص222). والنَّاذِرَِنِنِ إذا لم ألقههما دَمي

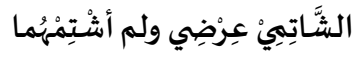


فالتفعيلات: متْفاعلن متْفاعلن متْفاعلن، والشاهد فيه نقل حركة الهمزة في: أَلْقهما إلى السـاكن قبلها: "لهُ"؛ كي يستقيم الوزن،

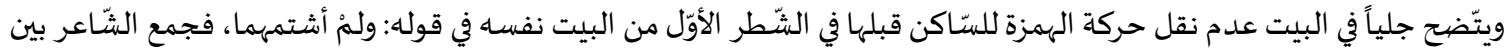

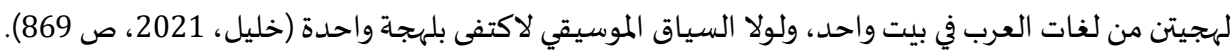

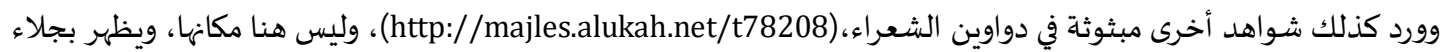

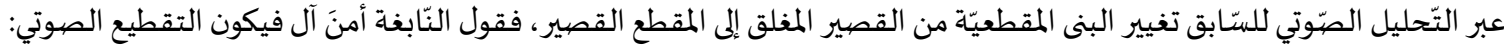
ص ح ص ح ص ح ح، وفي حال عدم النّقل يكون التقطيع الصّّوتي: ص ح ص ح ص ص ح ح، وفي الأبيات الأخرى فيتّضح بجلاء تغيير المقطع الصهوتي بعد النّقل من مقطع قصير مغلق إلى مقطع قصير، فيجمع الشّواهد السابقة أثر نقل حركة الهمزة للسّّاكن قبلها في

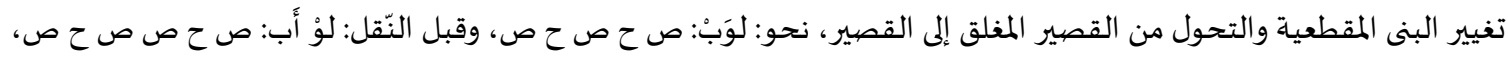

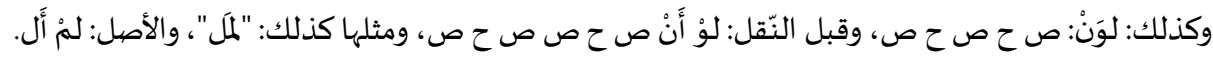

المطلب الثالث: هل نقل حركة الهمزة للساكن قبلها من الضر ائر؟

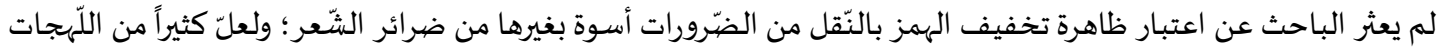

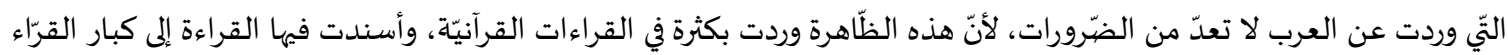

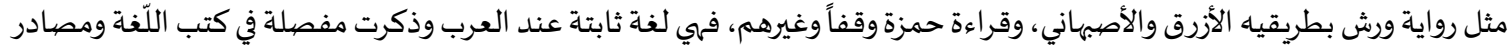

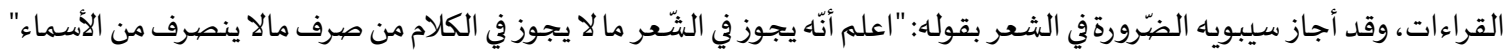
(سيبوياه، 1988، 32/1)، ثم ساق شواهد وردت عن العرب لا علاقة بظاهرة نقل حركة الهمزة فيها، كما يظهر للباحث انشغال النقاد ببيت النابغة الذبياني السـابق "أمن آل مية" بالحديث عن الإقواء في البيت الثاني دون الإشـارة إلى ظاهرة نقل الهمزة في البيت الأوّل

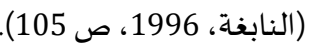

المطلب الر ابع: شروط نقل الهمزة وضيع القدماء شروطاً للنَّقل للهمزة، وسـار على دربهم بعض المحردئين، وهذا الشروط هي: (الداني، 1984، 1182/3، وأبو شامة،

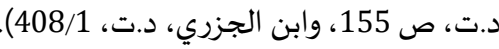
أولاً: أن يكون الحرف المنقول إليه ساكناً.

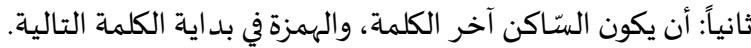

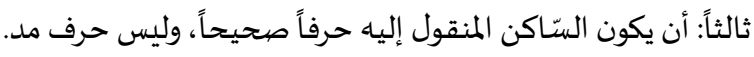

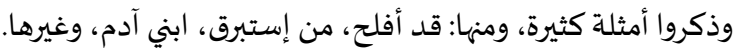

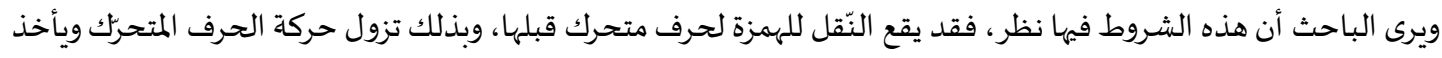

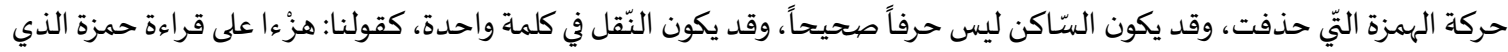

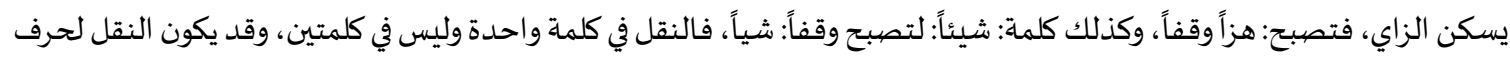

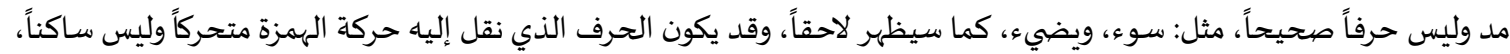

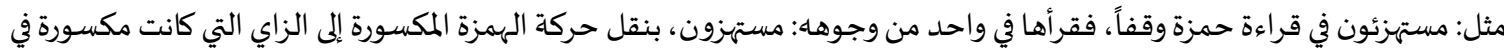

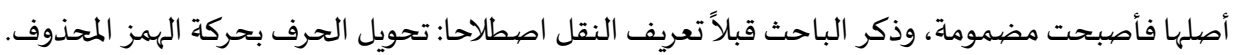

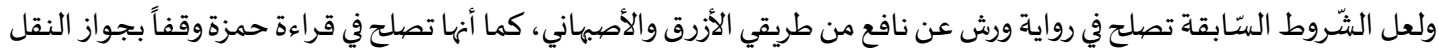
وهو أحد وجوهاه وقفاً، لكن جرت عادة اللاحقين عند حديثهم عن نقل الهمزة تعميم شروط نقل الهمزة عن ورش على على غيره من القراء، وهذا يحتاج إلى إعادة نظر.

\section{المطلب الخامس: سبب نقل حركة الهمزة لما قبلها وليس بعدها} أولاً: الابتعاد عن الالتباس بين الأبنية، فإن قلنا: قد أفلح، فإننا ننقل حركة الهمزة لما قبلها، فهرة فئقول: "قدَفْلح"، فلا يتغير المعنى، ويبقى

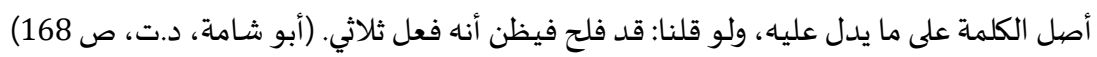

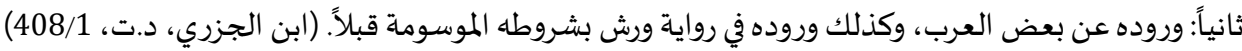

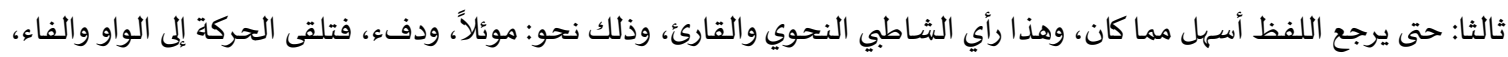

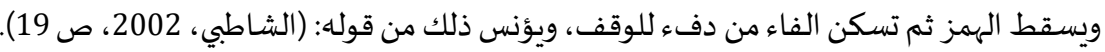
وحرِّك به ما قبْله متسكّناً ... وأسقطهُ حتَّى يرجع اللَّفظ أسهَاً 
تتبع الباحث أشكال نقل الهمزة في القراءات القرآنية فوجده يأخذ مساحة واسعاة في القراءات القرآنية؛ فورد في أصهول رواية ورش

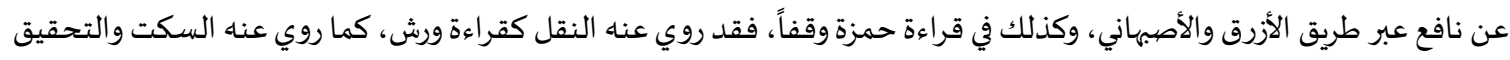

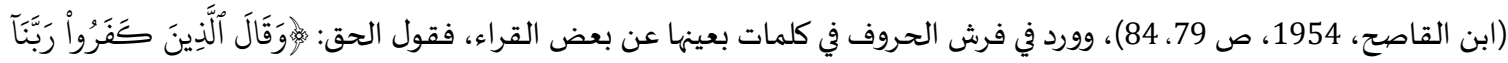

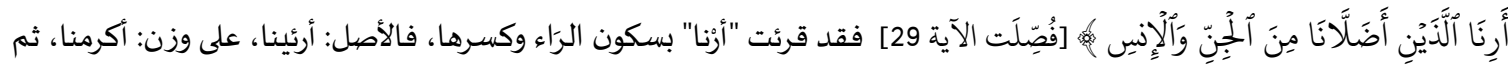

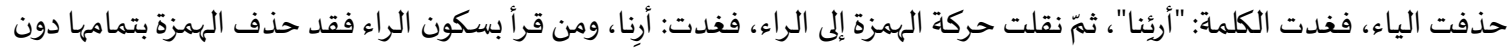

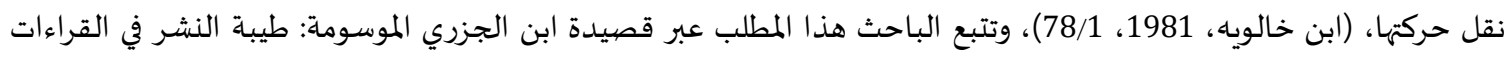

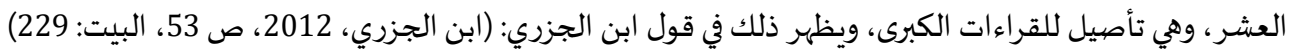

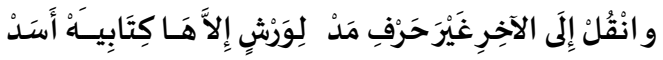

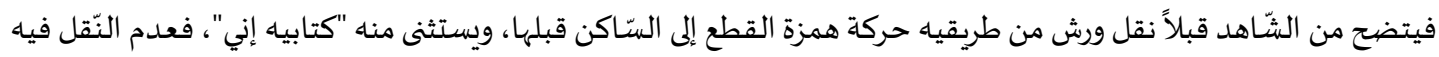

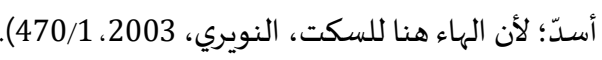

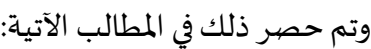

المطلب الأول: نقل حركة الهمزة للسّاكن قبلها في الكلمات التي دخلت عليها لام التّعريف

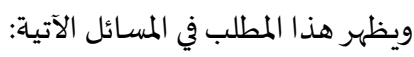

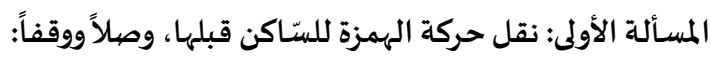

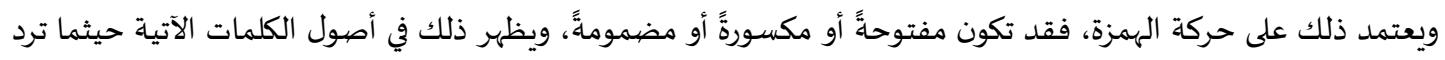

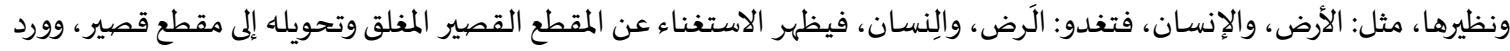

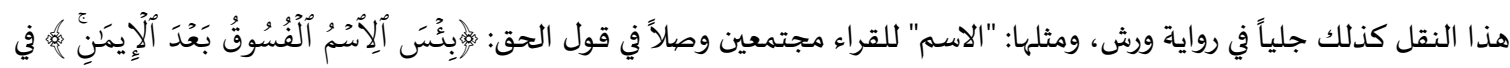

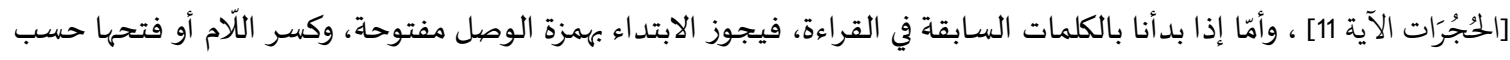

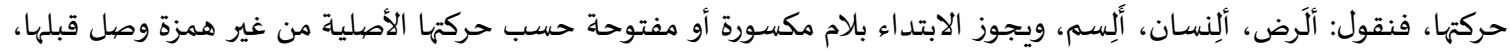

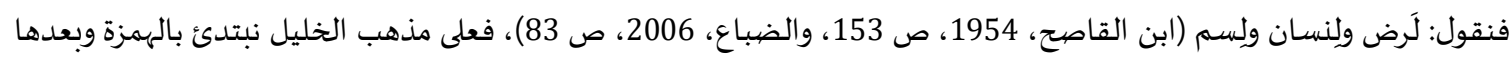

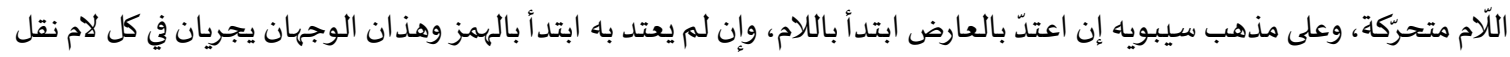

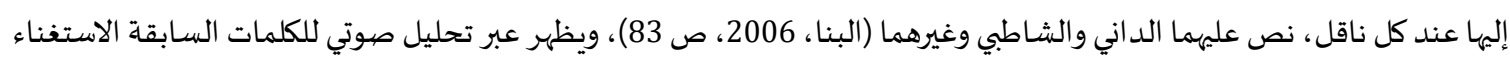

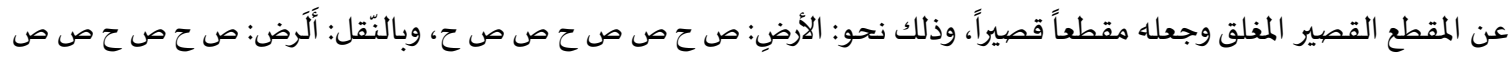

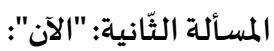

وتفيد الإخبار حيثما ترد في القرآن، وورد نقلها عن ورش، وورد عن الرّاوي ابن وردان عن أبي جعفر النّقل والتّحقيق (سالم، 2003،

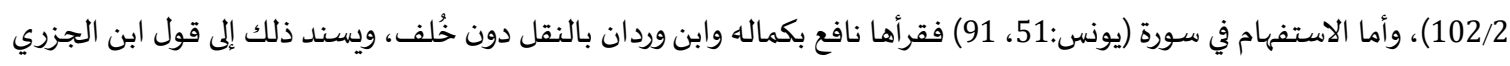

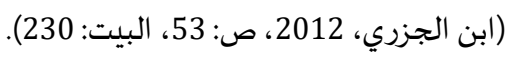

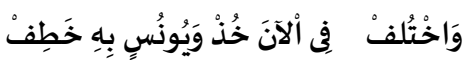

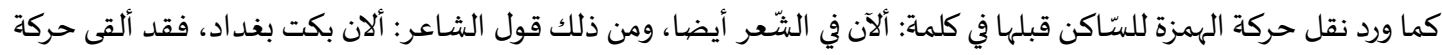

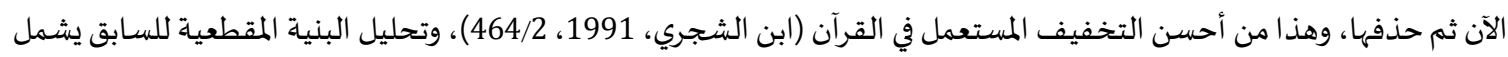
هذه الكلمة أيضاً.

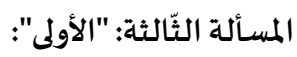

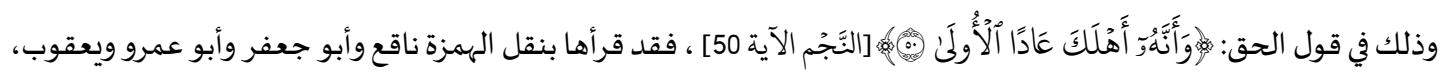

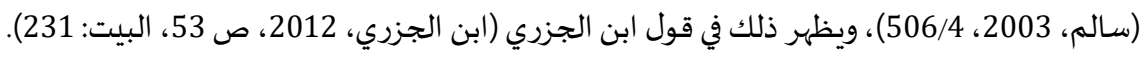

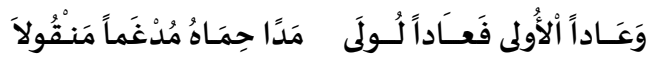


فيظهر جلياً عبر الأبيات قراءة هذه الكلمة: "عادالُّولى" بنقل حركة الضّم للهمزة على الواو للسّاكن قبلها، وهي لام التّعريف

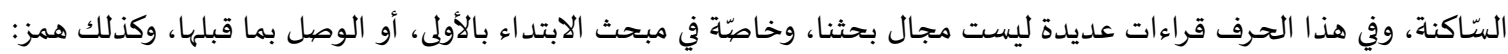

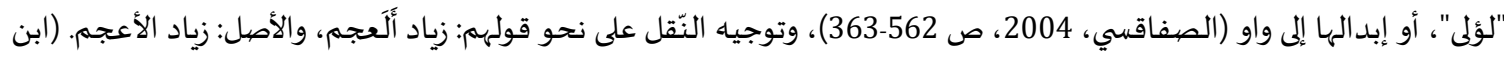
خالويه، 1981،

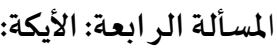

وردت هذه الكلمة في أربعة مواضع في القرآن الكريم، وورد عن ورش نقل حركة الهمزة للساكن قبلها، فقرأها: لَيكة، بدلاً من:

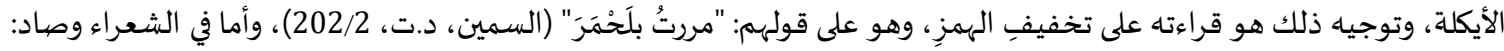

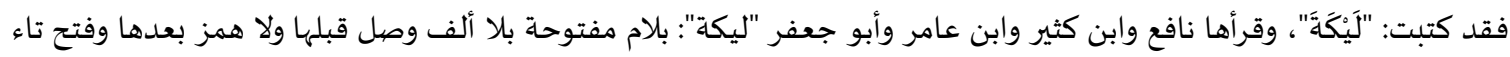
التأنيث غير منصرفة للعلمية والتأنيث كطلحة مضاف إليه لأصحاب (سالم، 2003، 643/3)، ويسند ذلك إلى قول ابن الجزري (ابن

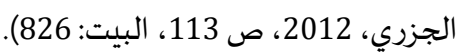

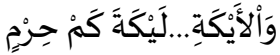

المطلب الثّاني: نقل حركة الهمزة للسيّاكن قبلها الموصول وقد يكون في كلمة أو كلمتين، ويظهر ذلك في المسائل الآتية:

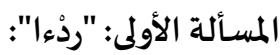

فقد قرأ نافع وأبو جعفر بنقل حركة الهمزة إلى الدال مع حذف الهمزة، "ردا"، ويعني: العون (ابن خالوياه، 1981، 278/1)، غير أبرائ

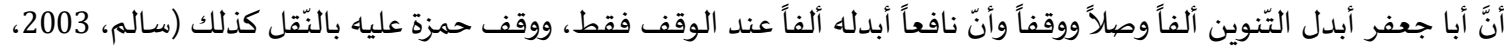

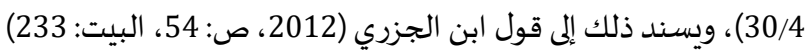
وَانْقُلْ مَدًا رِدَا وَثَبَبْتُ الْبَدَلْن

ويظهر بجلاء كذلك تحويل البنية المقطعيّة من قصير مغلق إلى قصير.

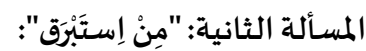

التي وردت عن ابن وردان وهو راوي القارئ أبي جعفر، فقرأها: منِسنتبرق كقراءة ورش (سالم، 2003، 523/4)، ويسند ذلك إلى إنى

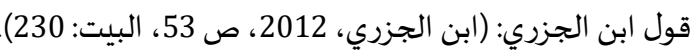
وَافَقَ مِنْ إِسنتَبْرَقِقِ غَرْ

المسألة الثّالثة: كتابيه إني":

في الحاقة/ 20-19، فقد ورد الخلف عن ورش بإسكان الهاء من غير نقل الحركة، أعني همزة إنّي إليها، كما ورد عنه النّقل طرداً

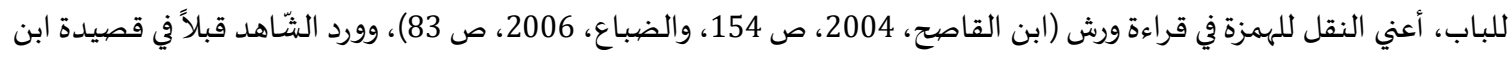

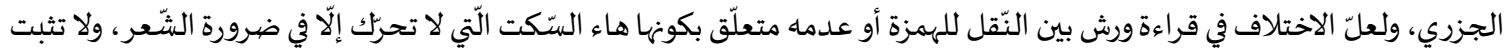

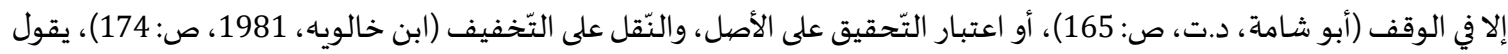

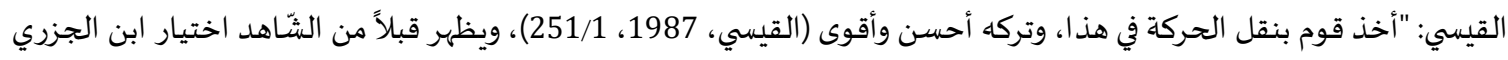
الإظهار بقوله: "أسد"، وقال في النّشر: وترك النّقل فيه هو المختار عندنا، والأصحّ لدينا والأقوى في العربيّة؛ لأنّ هاء السّكت حكمها

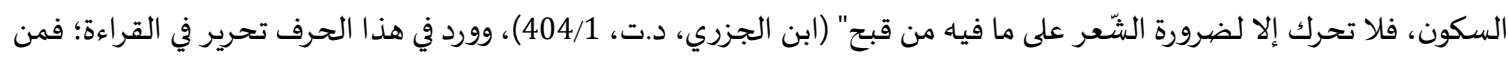
حقّق الهمزة أظهر قول الحق: "مالية هلك"، مع الاعتداد بسكتة يسيرة دون تنّفس على الهاء الأولى، ومن نقل أدغم الهاء في الهاء، وهو

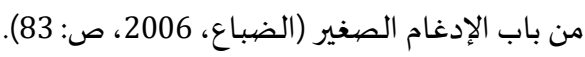

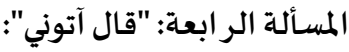

في الكهف/ 96: ويؤنس ذلك في قول ابن الجزري. (ابن الجزري، 2012، البيت: 758)

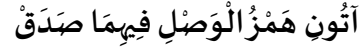
ففي قراءة حمزة وشعبة بخلف عنه بهمزة ساكنة مع بقاء فتحة اللام على حالها، "قالاتوني". المسـألة الخامسـة: "ملء": في قول الحق: "ملء الأرض"، وورد ذلك من طريق الهاء الأصبهاني عن ورش، ورواية ابن وردان كما يشير ابن الجزري في الأبيات السابقة،

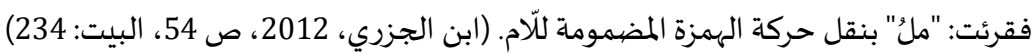


المسـألة الستّادسـة: "واسْـأل":

حيثما ترد في القرآن، فقرئت: وَسَل، ووردت في قراءة الكسائي وخلف العاشر والمكي، ويؤنس ذلك في قول ابن الجزري: (ابن

الجزري، 2012، ص 54، البيت: 234).

وَسََلْ رَوَى دُمْ كَيْفَ

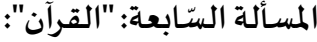

في قراءة المكي الذي قرأها: القران (وغيث النفع، ص 101)، ويظهر ذلك في قول ابن الجزري: (ابن الجزري، 2012، ص 54، البيت:

\section{كيف جَا الْقُرَانُ دُفْ}

يتّضح قبلاً اختلاف القراءات القرآنيّة بين نقل حركة الهمزة للساكن قبلها أو تحقيقها، ويظهر أنها وردت بكثرة في قراءة أهل

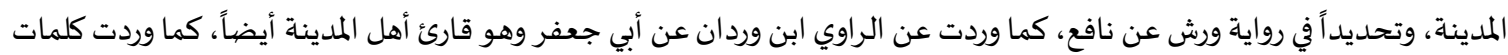

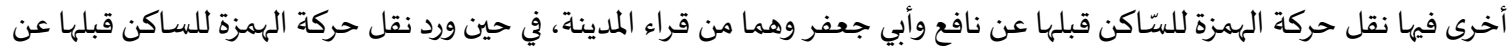

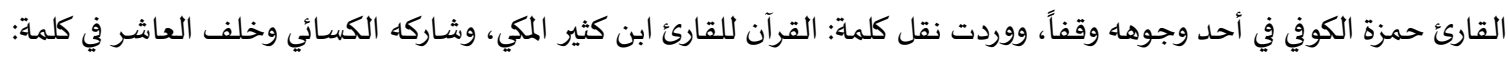

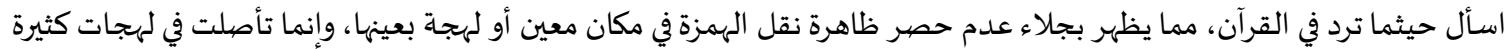

في مكة والمدينة والعراق.

المطلب الثالث: نقل حركة الهمزة للساكن قبلها فقط في حالة الوقف وذلك جلي في قراءة حمزة وقفاً، ويظهر في المسائل الآتية:

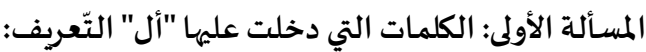
كقولنا: الأرض، الآخرة، فله فهها النّقل وقفا، وله كذلك أحكام التهام أخرى، مثل: السّّكت على ما قبل الهمز المتحرك أو تحقيق الهمز

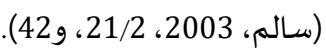

المسألة الثّانية: الكلمات التّي تحوي همزة متحركّة وسط الكلمة:

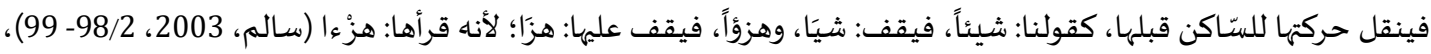

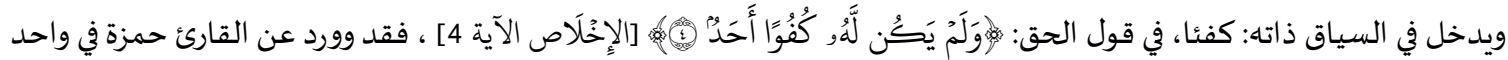

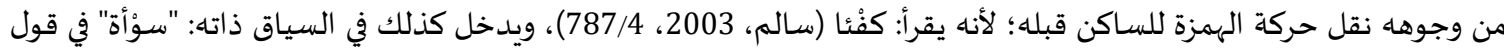

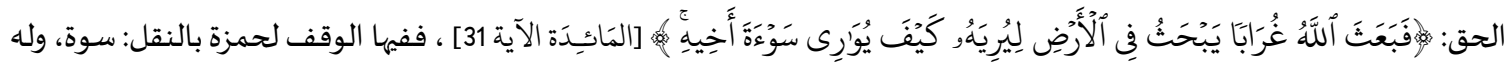

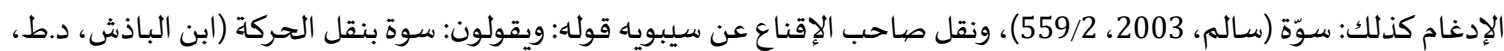

ص ص 104) (104)

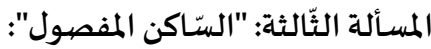

من كلمتين فقراءة حمزة التّحقيق للسّاكن المفصول، وهو مقدم، نحو: من آمن، وقد أفلح، عذابُّ أليم، عليكم أنفسكم، وله النها

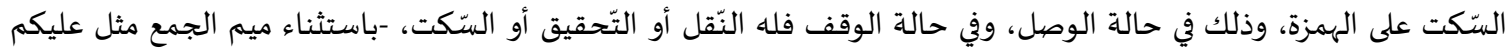

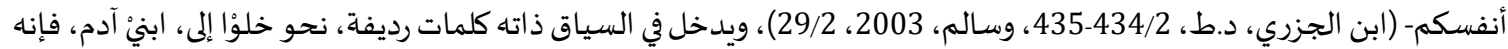

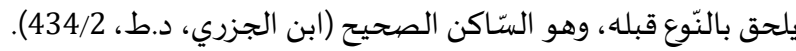

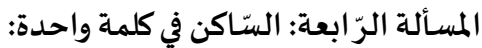

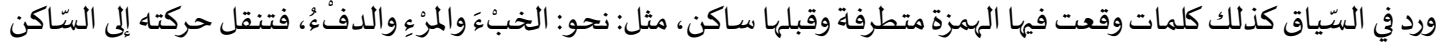

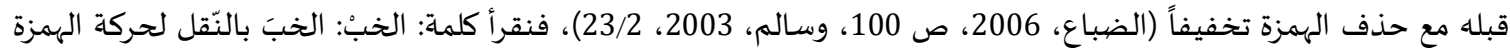

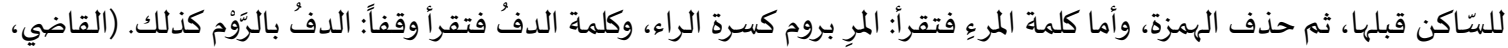
د.ط، ص: 37، و178، و و235).

المطلب الرّ ابع: نقل حركة الهمزة للمتحرّك قبلها حال الوقف للقارئ حمزة

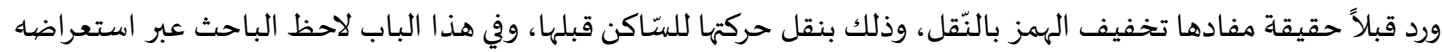

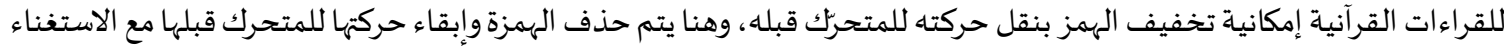
عن حركة ما قبلها، فتبقى حركة الهمزة، سواء كانت تلك الحركة ضماء أو فتحة أو كسرة، والذي يظهر للباحث في هذا البهاب الباب، وهو 
الجديد في بحثه حصر السابقين تخفيف الهمز بنقل حركتها للسّّاكن قبلها، غير أنه يظهر في الحروف التي سيعرضها لاحقا نقل حركتها للمتحرّك قبلها، وفي هذا المطلب المسبائل الآتية:

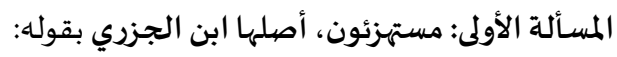

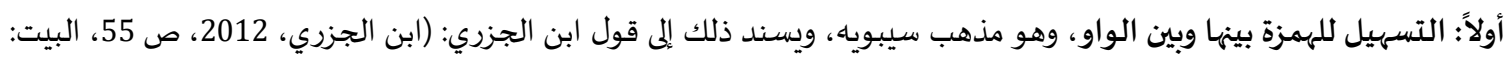

وعنْه تسهيلٌ كخط المصحف. ثانياً: إبدال الهمزة ياء مضممومة، وهو مذهب الأخفش، ويسند ذلك إلى قول ابن الجزري: (ابن الجزري، 2012، ص 55، البيت: 245). ونقلْ ... ياءُ كيطفِئوا

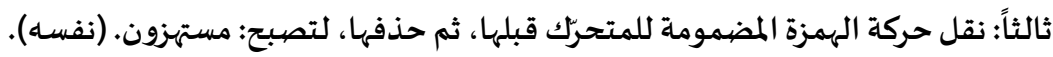

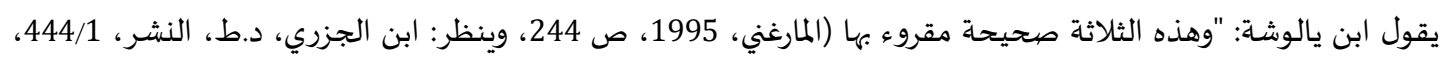

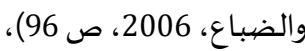

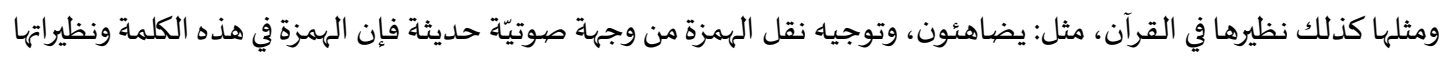

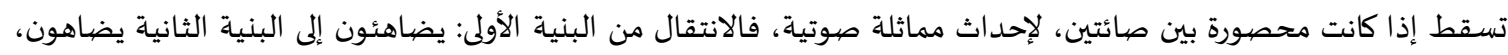

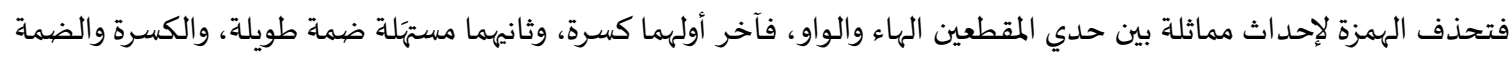

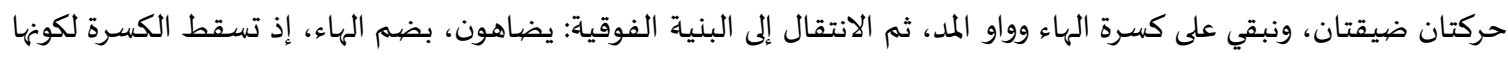

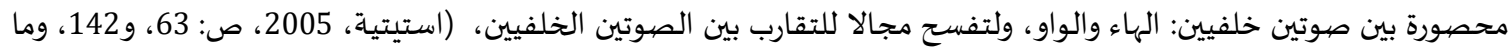

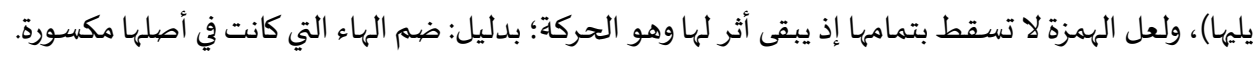

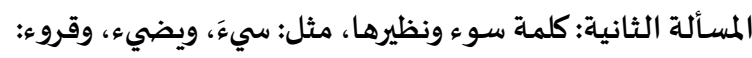

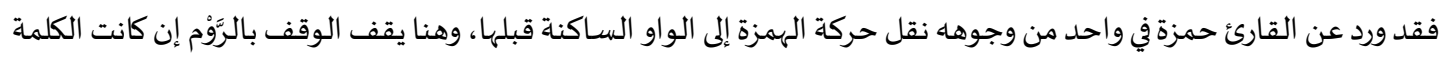

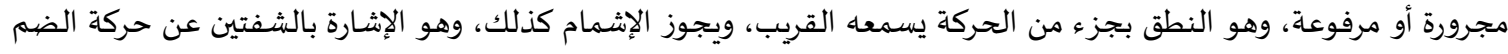

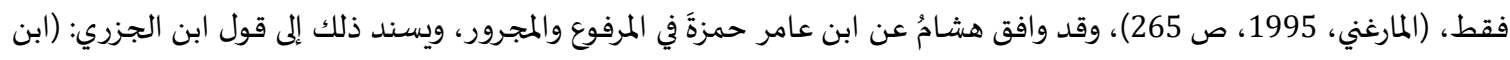

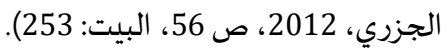
ومِثله خُلف هشام في الطُّرف

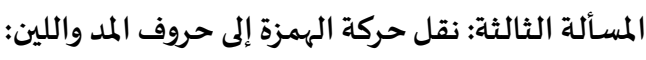

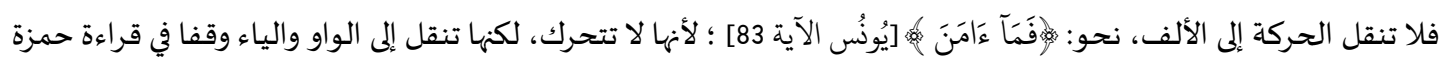

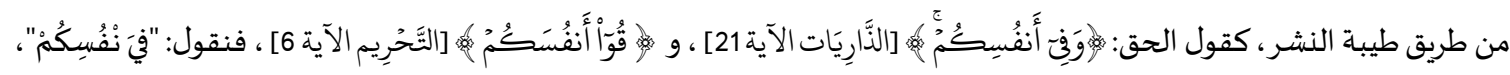

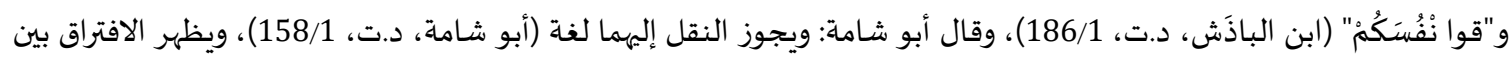

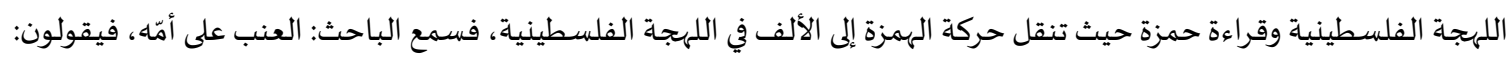

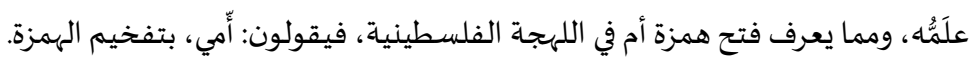
المطلب الرّا ابع: نقل حركة الهمزة لما قبلها في القراءات غير المتو اترة

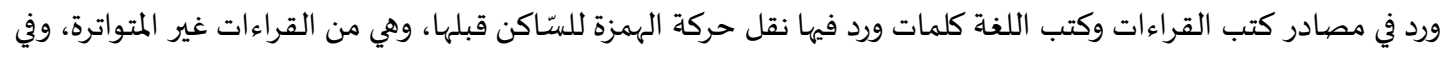

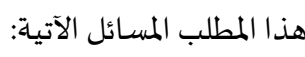

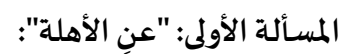

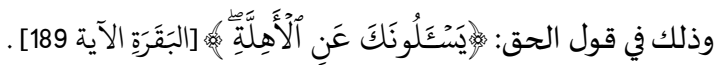

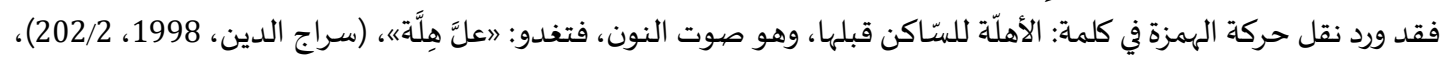

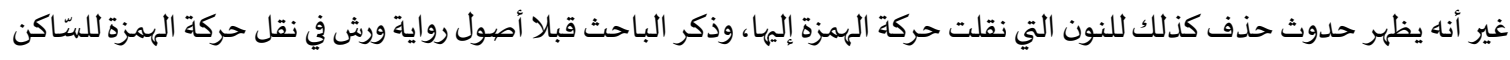

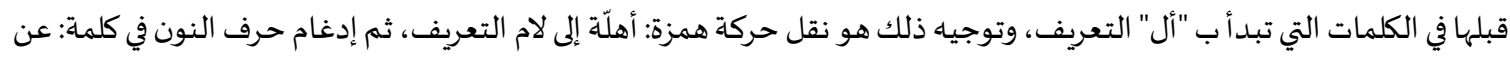

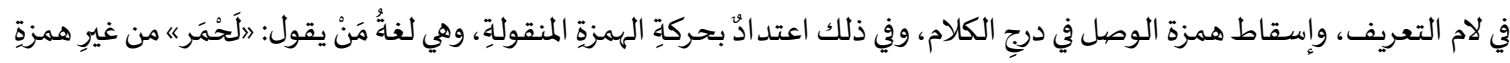

وصلٍ، (سراج الدين، 1998، 202/2). 


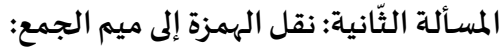

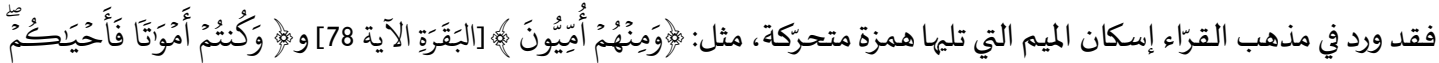

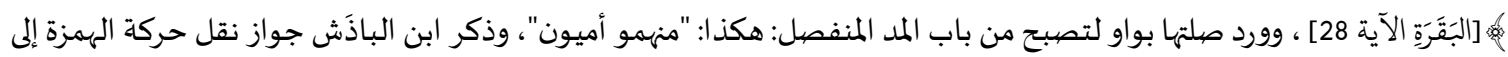

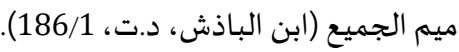

\section{المبحث الثالّث: نقل الهمزة في اللّهجة الفلسطينيّة}

تمتاز اللّرجة الفلسطينيّة كفيرها من اللّهجات الحديثة بمجموعة من الستّمات اللّغويّة التّتي لها نظام صوتيّ خاصنّ بها، وترتبط

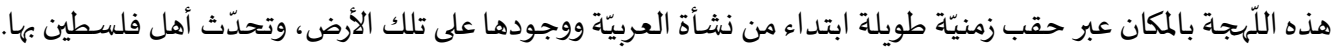

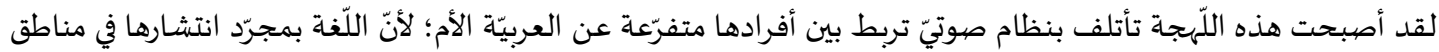

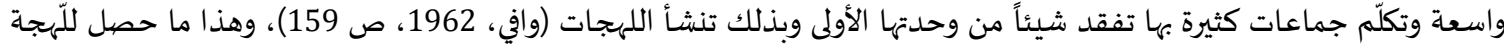

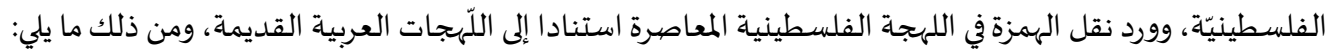

المطلب الأول: الكلمات الدّاخلة عليها أل التعريف

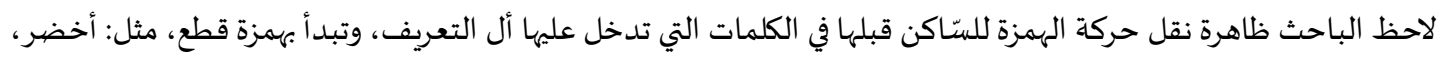

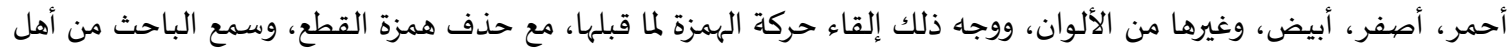

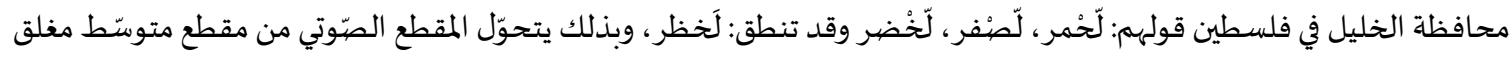

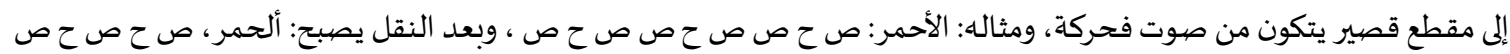

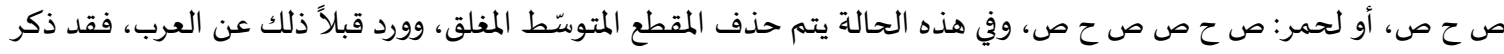

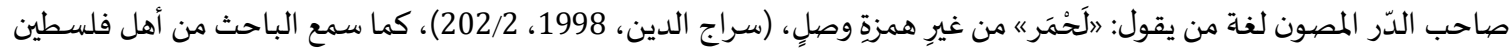

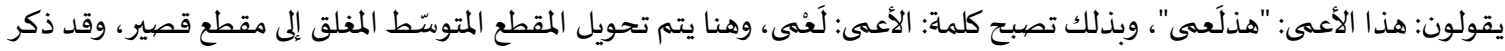

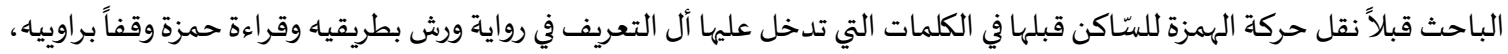

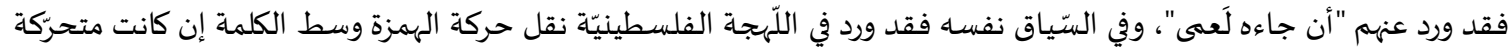

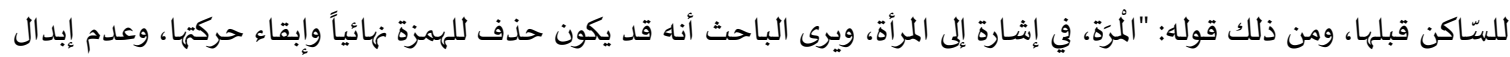

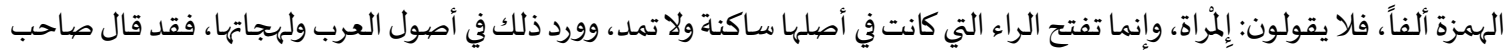

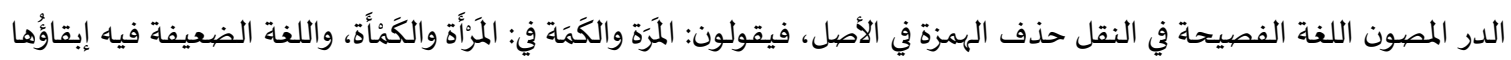

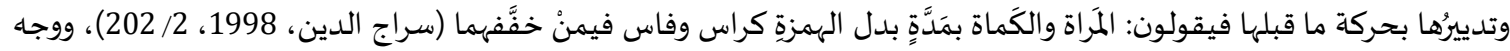

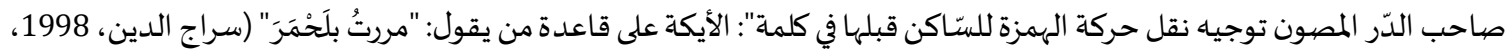

$(202 / 2$

المطلب الثاني: نقل حركة الهمزة للكلمات التي تبدأ بهمزة قطع

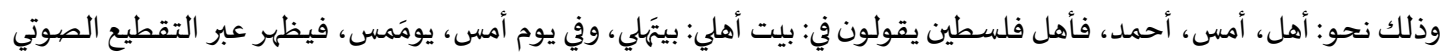

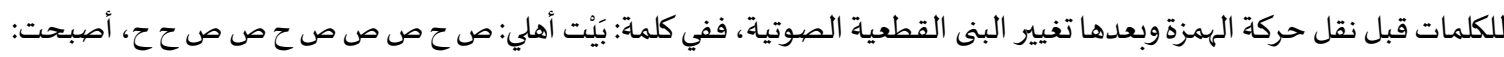

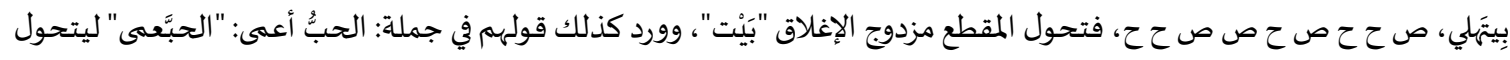

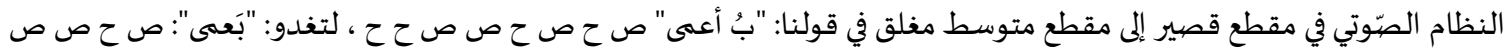

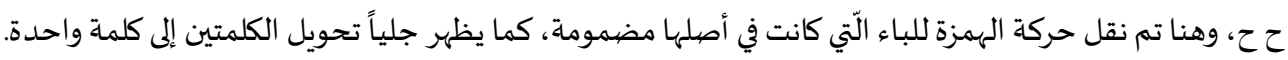

المطلب الثّالث: نقل حركة الهمزة للسّاكن قبلها حال النداء

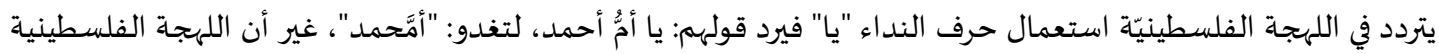

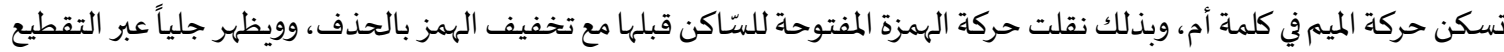

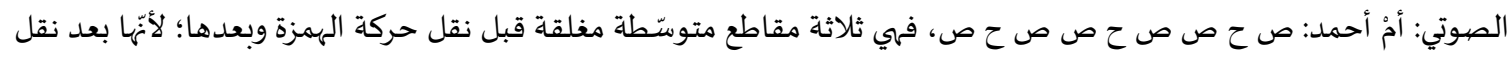

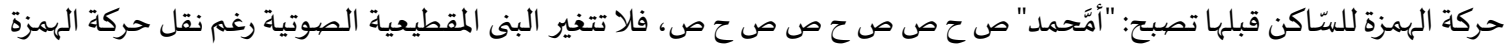

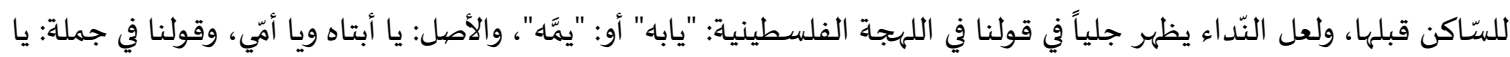


إخوان: ياخُوان، غير أنه من الجلاء اعتبار حذف الهمزة مع حركتها وليس نقل الهمزة في قولنا: ياخوان، ومثلها قول أهل فلسطين: العنب

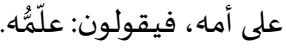

المطلب الرّابع: نقل حركة الهمزة للسّاكن قبلها في كلمات أخرى مستعملة

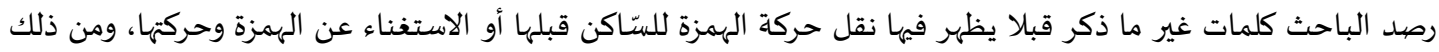

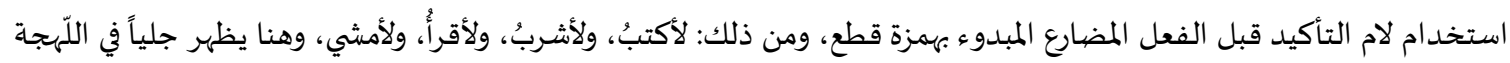

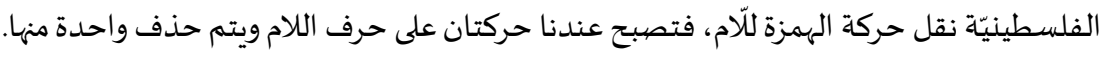

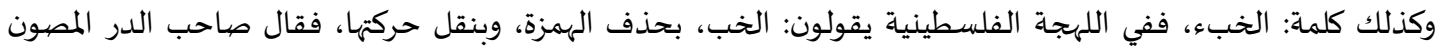

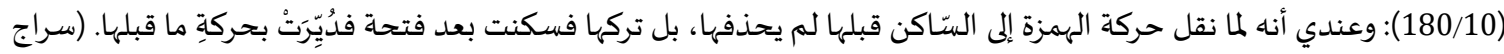

الدين، 1998، 180/10)

تم بحمد الله الانتهاء من هذا البحث، وفيما يلي مجموعة من النتائج التي توصل الباحث إلهيا: نتائج البحث:

الهمزة صوت أساسي في النظام الصوتي للهجة الفلسطينية رغم ميل اللهّجة الفلسطينية إلى نقل حركتها للسّّاكن قبلها.

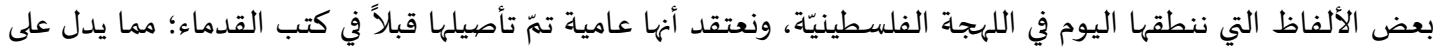
فصاحتها، مثل: لَّحمر وغيرها.

ت تتأصل ظاهرة نقل حركة الهمزة للسّاكن قبلها في القراءات القرآنيّة والشّّعر العربي ونطق العرب قديماً واللّهجة الفلسطينيّة.

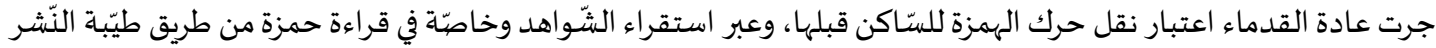
فإن حركة الهمزة قد تنتقل للمتحرك قبلها، وليس بالضِّرورة أن يكون ساكناً.

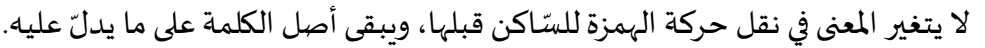
يؤدّي نقل حركة الهمزة للسّاكن قبلها إلى تفيير البنى المقطعيّة للكلمة، وغالبا ما يتم تحويل المقطع القصير المغلق إلى مقطع قصير.

1. استيتية، سمير (2005). القراءات القرآنية بين العربية والأصوات اللغوية. عالم الكتب، إربد، د.ط. 2.

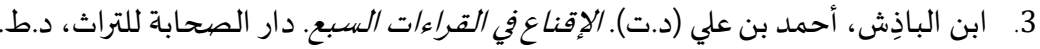

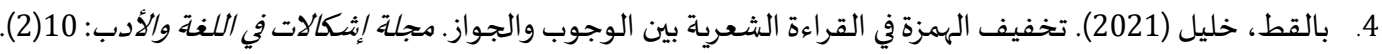

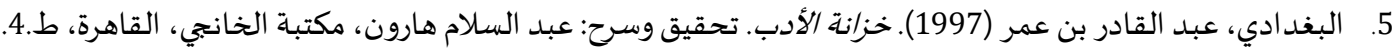
6. البنا، أحمد بن محمد (2006). إتحاف فضلاء البشر في القراءات الأربعة عشر. تحقيق: أنس مهرة، دار الكتب العلمية، لبنان،

7. ابن الجزري، محمد بن محمد (2012). طيّبة النشرفي القراءات العشّر. تصحيح ومراجعة: محمد تميم الزعبي، دار ابن الجزري،

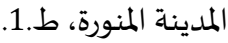

8. ابن الجزري، محمد بن محمد (د.ت). النشرفي القراء/ت العشر. تحقيق: علي الضباع، المطبعة التجارية الكبرى، د.ط.

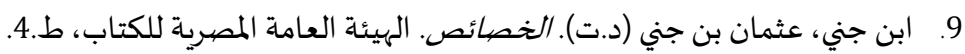

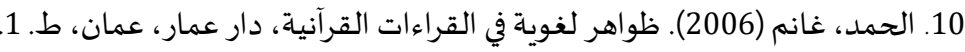

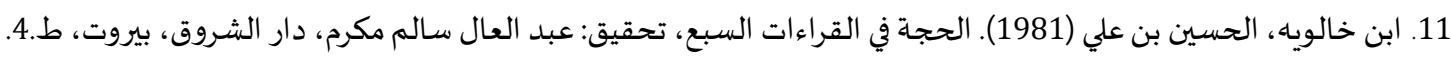

12. الداني، عثمان بن سعيد (1984). التيسير في القراء/ت السبع. تحقيق: أوتو تربزل، دار الكتاب العربي، بيروت، ط.2.2.

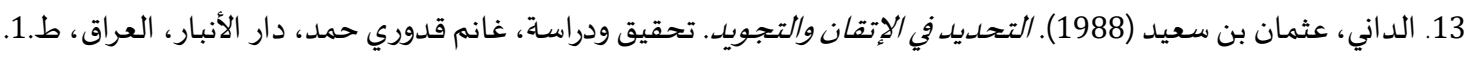

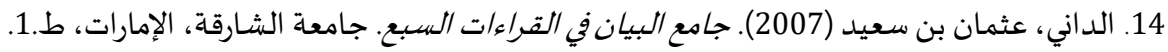
15. بن زهير، كعب (1997). ديوان كعب بن زهير. تحقيق وشرح: علي فاغور، د.ط. 
16. سالم، محمد إبراهيم، (2003). فريدة الدهرفي تأصيل وجمع القراءات العشـر. دار البيان العربي، القاهرة، ط.1. 17. سراج الدين، عمر بن علي (1998). اللباب في علوم الكتاب. تحقيق: عادل أحمد وعلي محمد، دار الكتب العلمية، بيروت، ط.1.1. 18. السمين، أحمد بن يوسف (د.ت). الدر المصبون في علوم الكتاب المكنون. تحقيق: أحمد الخراط، دار القلم، دمشق، د.اط.

19. سيبوياه، عمرو بن عثمان (1988). الكتاب. تحقيق: عبد السلام محمد هارون، مكتبة الخانجي، القاهرة، ط3. 20. الشاطبي، القاسم بن فيره (2005). حرز الأماني ووجه التهاني في القراء/ت السبع. تحقيق: محمد تميم الزعبي، مكتبة دار الهدى ودار الغوثاني للدراسات القرآنية، طباسن.

21. أبو شامة، عبد الرحمن بن إسماعيل (د.ت). إبراز المعاني من حرز الأماني. دار الكتب العلمية، د.ط.

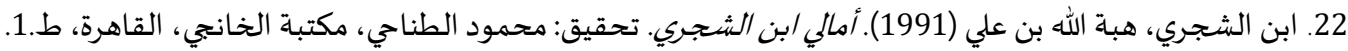
23. بن شـداد، عنترة (1964). ديوان عنترة، تحقيق ودراسـة: محمد مولوي، المكتب الإسلامي، د.ط.

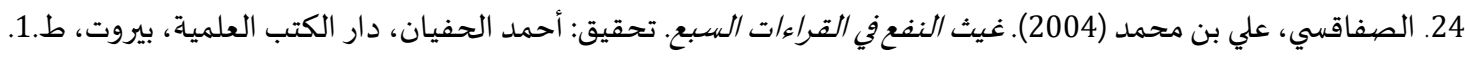
25. الضباع، علي محمد (2006). إرشاد المريد إلى مقصود القصيد. تحقيق: إبراهيم عطوة عوض، مكتبة مصطفى الحلبي، القاهرة.

26. العبيدي، عادل (2005). الظواهر الصبوتية والصرفية في قراءة الجحدري. مكتبة الثقافة، القاهرة، ط.1.

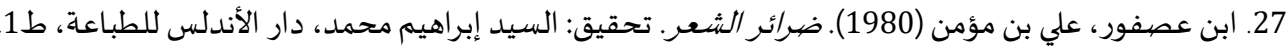
28. الفراهيدي، الخليل بن أحمد (د.ت).كتاب العين. تحقيق: مهدي المخزوم وإبراهيم السامرائي، دار ومكتبة الهلال، د.ت. 29. ابن القاصح، عثمان بن محمد (2004). سراج القارئ المبتدي وتذكار المقرئ المنتهي، دار الصحابة للتراث، طنطا، ط1.

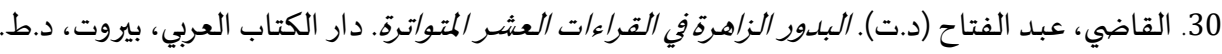
31. قيس بن الملح (د.ت). ديوان مجنـون ليلى. جمع وتحقيق: عبد الستار فراج، مكتبة مصر، القاهرة، د.ط. 32. القيسي، مكي بن أبي طالب (1987). الكشف عن وجوه القراء/ت السبع وعللها وحجدها. تحقيق: محيي الدين رمضان، مؤسيسة

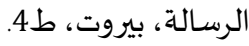

33. المارغني، سيدي إبراهيم (1995). النجوم الطوالع على الدرر اللوامع. دار الفكر، بيروت.

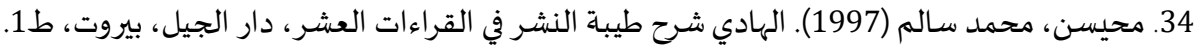

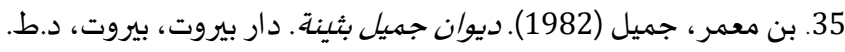

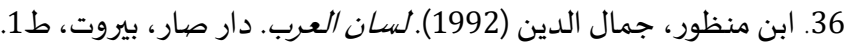
37. النابغة الذبياني (1996). ديوان النابغة الذبياني، شرح وتقديم: عباس عبد الستار، دار الكتب العلمياة، بيروت، ط3.

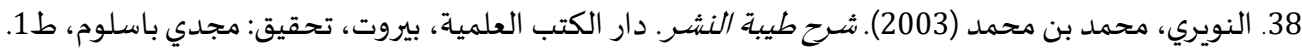

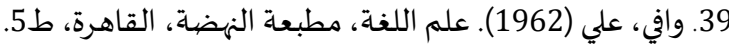
40. اليحصبي، عياض بن موسى (د.ت). مشارق الأنوار على صحاح الآثار، المكتبة العتيقة ودار التراث، د.ط.

ثانياً: المو اقع الإلكترونية: - م

1. www.members.lycos.co.uk/atmanalfahd/alasbhany.rm 


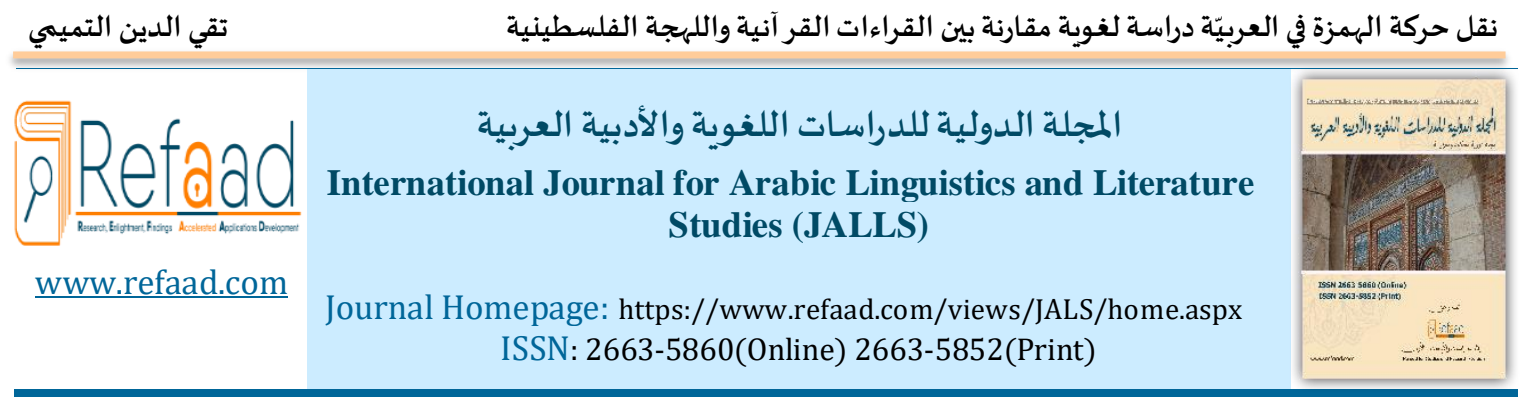

\title{
Transferring the hamza "A" in the Arabic language A linguistic study comparing the Quranic readings with the Palestinian dialect
}

\author{
Taqi eddin Mustafa Abdelbaset Al-Tamimi \\ Associate Professor, Palestine Technical University, Kadoori- Al Aroub Branch, Palestine \\ taqitammi@gmail.com
}

Received : 4/11/2021 Revised : 7/12/2021 Accepted: 19/12/2021 DOI : https://doi.org/10.31559/JALLS2021.3.4.2

\begin{abstract}
This study combines the originality and the heritage represented in transferring the hamza " glottal stop" to the previous consonant in the modern Palestinian dialect. Also, it connects this to Arabic poetry and the ten major readings from the path of the Tyibt Al-nshr through Ibn al-Jazari's tagged poem. Then the interpretation of this is a phonetic interpretation based on the ancients' opinions and the modernists' guidance which shortens the hamza "glottal stop" in Arabic, which is a widespread doctrine, as the hamza "glottal stop" is shortened by replacement, transfer, deletion, insertion, and others.
\end{abstract}

Keywords: hamza "A" Transferring; Dialect; Quran Readings.

\section{References:}

1. Al'bydy, 'adl (2005). Alzwahr Alswtyh Walsrfyh Fy Qra't Aljhdry. Mktbt Althqafh, Alqahrh, T.1.

2. Abn 'sfwr, 'ly Bn M'mn (1980). Dra'r Alsh'r. Thqyq: Alsyd Ebrahym Mhmd, Dar Alandls Lltba'h, T1.

3. Astytyh, Smyr (2005). Alqra'at Alqranyh Byn Al'rbyh Walaswat Allghwyh. 'alm Alktb, Erbd, D.T.

4. Anys, Ebrahym (1990). Alaswat Allghwyh. Mktbh Alanjlw Almsryh, T.3, Alqahrh.

5. Abn Albadsh, Ahmd Bn 'ly (D.T). Aleqna' Fy Alqra'at Alsb'. Dar Alshabh Lltrath, D.T.

6. Balqt, Khlyl (2021). Tkhfyf Alhmzh Fy Alqra'h Alsh'ryh Byn Alwjwb Waljwaz. Mjlt Eshkalat Fy Allghh Waladb: 10(2).

7. Albghdady, 'bd Alqadr Bn 'Emr (1997). Khzant Aladb. Thqyq Wsrh: 'bd Alslam Harwn, Mktbt Alkhanjy, Alqahrh, T.4.

8. Albna, Ahmd Bn Mhmd (2006). Ethaf Fdla' Albshr Fy Alqra'at Alarb'h 'shr. Thqyq: Ans Mhrh, Dar Alktb Al'Imyh, Lbnan, T.3.

9. Aldany, 'thman Bn S'yd (1984). Altysyr Fy Alqra'at Alsb'. Thqyq: Awtw Trbzl, Dar Alktab Al'rby, Byrwt, T.2.

10. Aldany, 'thman Bn S'yd (1988). Althdyd Fy Aletqan Waltjwyd. Thqyq Wdrash, Ghanm Qdwry Hmd, Dar Alanbar, Al'raq, T.1.

11. Aldany, 'thman Bn S'yd (2007). Jam' Albyan Fy Alqra'at Alsb'. Jam't Alsharqh, Alemarat, T.1.

12. Aldba', 'ly Mhmd (2006). Ershad Almryd Ela Mqswd Alqsyd. Thqyq: Ebrahym 'twh 'wd, Mktbt Mstfa Alhlby, Alqahrh. T1.

13. Alfrahydy, Alkhlyl Bn Ahmd (D.T). Ktab Al'yn. Thqyq: Mhdy Almkhzwm Webrahym Alsamra'y, Dar Wmktbt Alhlal, D.T.

14. Alhmd, Ghanm (2006). Zwahr Lghwyh Fy Alqra'at Alqranyh, Dar 'mar, 'man, T. 1.

15. Abn Aljzry, Mhmd Bn Mhmd (2012). Tybh Alnshr Fy Alqra'at Al'shr. Tshyh Wmraj'h: Mhmd Tmym Alz'by, Dar Abn Aljzry, Almdynh Almnwrh, T.1. 
16. Abn Jny, 'thman Bn Jny (D.T). Alkhsa's. Alhy'h Al'amh Almsryh Llktab, T.4.

17. Abn Aljzry, Mhmd Bn Mhmd (D.T). Alnshr Fy Alqra'at Al'shr. Thqyq: 'ly Aldba', Almtb'h Altjaryh Alkbra, D.T.

18. Abn Khalwyh, Alhsyn Bn 'ly (1981). Alhjh Fy Alqra'at Alsb', Thqyq: 'bd Al'al Salm Mkrm, Dar Alshrwq, Byrwt, T.4.

19. Bn M'mr, Jmyl (1982). Dywan Jmyl Bthynh. Dar Byrwt, Byrwt, D.T.

20. Almarghny, Sydy Ebrahym (1995). Alnjwm Altwal' 'la Aldrr Allwam'. Dar Alfkr, Byrwt.

21. Mhysn, Mhmd Salm (1997). Alhady Shrh Tybt Alnshr Fy Alqra'at Al'shr, Dar Aljyl, Byrwt, T1.

22. Abn Mnzwr, Jmal Aldyn (1992). Lsan Al'rb. Dar Sar, Byrwt, T1.

23. Alnabghh Aldbyany (1996). Dywan Alnabghh Aldbyany, Shrh Wtqdym: 'bas 'bd Alstar, Dar Alktb Al'lmyh, Byrwt, T3.

24. Alnwyry, Mhmd Bn Mhmd (2003). Shrh Tybt Alnshr. Dar Alktb Al'lmyh, Byrwt, Thqyq: Mjdy Baslwm, T1.

25. Alqady, 'bd Alftah (D.T). Albdwr Alzahrh Fy Alqra'at Al'shr Almtwatrh. Dar Alktab Al'rby, Byrwt, D.T.

26. Abn Alqash, 'thman Bn Mhmd (2004). Sraj Alqar' Almbtdy Wtdkar Almqr' Almnthy, Dar Alshabh Lltrath, Tnta, T1.

27. Qys Bn Almlh (D.T). Dywan Mjnwn Lyla. Jm' Wthqyq: 'bd Alstar Fraj, Mktbt Msr, Alqahrh, D.T.

28. Alqysy, Mky Bn Aby Talb (1987). Alkshf 'En Wjwt Alqra'at Alsb'W'llha Whjjha. Thqyq: Mhyy Aldyn Rmdan, M'sst Alrsalh, Byrwt, T4.

29. Salm, Mhmd Ebrahym, (2003). Frydt Aldhr Fy Tasyl Wjm' Alqra'at Al'shr. Dar Albyan Al'rby, Alqahrh, T.1.

30. Alsfaqsy, 'ly Bn Mhmd (2004). Ghyth Alnf' Fy Alqra'at Alsb'. Thqyq: Ahmd Alhfyan, Dar Alktb Al'lmyh, Byrwt, T.1.

31. Alshatby, Alqasm Bn Fyrh (2005). Hrz Alamany Wwjh Althany Fy Alqra'at Alsb'. Thqyq: Mhmd Tmym Alz'by, Mktbh Dar Alhda Wdar Alghwthany Lldrasat Alqranyh, T4.

32. Abw Shamh, 'bd Alrhmn Bn Esma'yl (D.T). Ebraz Alm'any Mn Hrz Alamany. Dar Alktb Al'Imyh, D.T.

33. Abn Alshjry, Hbh Allh Bn 'ly (1991). Amaly Abn Alshjry. Thqyq: Mhmwd Altnahy, Mktbt Alkhanjy, Alqahrh, T.1.

34. Bn Shdad, 'ntrh (1964). Dywan 'ntrh, Thqyq Wdrash: Mhmd Mwlwy, Almktb Aleslamy, D.T.

35. Alsmyn, Ahmd Bn Ywsf (D.T). Aldr Almswn Fy 'lwm Alktab Almknwn. Thqyq: Ahmd Alkhrat, Dar Alqlm, Dmshq, D.T.

36. Sraj Aldyn, 'mr Bn 'Ely (1998). Allbab Fy 'lwm Alktab. Thqyq: 'adl Ahmd W'ly Mhmd, Dar Alktb Al'lmyh, Byrwt, T.1.

37. Sybwyh, 'mrw Bn 'Ethman (1988). Alktab. Thqyq: 'bd Alslam Mhmd Harwn, Mktbt Alkhanjy, Alqahrh, T3.

38. Wafy, 'ly (1962). 'lm Allghh, Mtb't Alnhdh, Alqahrh, T5.

39. Alyhsby, 'yad Bn Mwsa (D.T). Msharq Alanwar 'la Shah Alathar, Almktbh Al'tyqh Wdar Altrath, D.T.

40. Bn Zhyr, K'b (1997). Dywan K'b Bn Zhyr. Thqyq Wshrh: 'ly Faghwr, D.T. 